\title{
ELBOW JOINT POSITION AND HAND PRESSURE FORCE SENSE UNDER CONDITIONS OF QUICK REACTION IN TABLE TENNIS PLAYERS
}

\author{
Ziemowit Bańkosz and Tadeusz Stefaniak \\ Department of Physical Education and Sports, \\ University School of Physical Education in Wrocław, Poland
}

Original scientific paper

DOI: $10.26582 / \mathrm{k} .53 .1 .12$

\begin{abstract}
:
Joint position sense and force reproduction are the most commonly used measures of proprioception. It is interesting to measure proprioception in integration of the factors most commonly viewed as the most important in table tennis - speed, in particular quick reaction. The aim of this study was to evaluate the accuracy of replication of a specific range of motion and force of hand pressing under conditions of limited time. Forty table tennis players and 30 non-athletes participated in the study. Electrogoniometric and dynamometric methods were used in the investigation. The accuracy of replication of pronation and supination movements of the forearm at the elbow joint and force of hand pressing under conditions of limited time (performing the activity as fast as possible in response to visual signals) were measured. The tests performed in the study revealed that both female and male table tennis players were characterized by a higher level of forearm position sense during performing the fastest possible pronation and supination movements in most of the tasks. Better results of table tennis players than of the control group suggest that joint position and hand pressure sense integrated with quick reaction are important performance factors in table tennis. The results also indicate opportunities for using this methodology to monitor training.
\end{abstract}

Key words: proprioception, sport, lateral differentiation, laterality, table tennis

\section{Introduction}

Table tennis is a very difficult sport. It is considered the fastest sport among sports games (Faber, Nijhuis-Van Der Sanden, Elferink-Gemser, Oosterveld, 2015; Kondric, Zagatto, \& Sekulić, 2013). The athlete has to respond very quickly in constantly changing playing conditions that are strongly affected by the opponent's actions. Many factors are involved in the achievement of sports skill at a high level, however, the factors that affect table tennis results, which have been evaluated most frequently in the literature, include different manifestations of speed: reaction time (Ak \& Kocak, 2010; Bhabhor, et al., 2013; Can, Kilit, Arslan, \& Suveren, 2013; Erdil, Durusoy, \& Acar, 1991), anticipation, and movement speed (Akpinar, Devrilmez, \& Kirazci, 2012; Łapszo, 2002).

Many authors have emphasized various modifications of sense, such as ball sense, equipment sense, and sense of the opponent as the factors that are important for playing sport and reaching champion level (not only in table tennis, but also in other sports-Hudetz, 2005; Panics, Tallay,
Pavlik, \& Berkes, 2008; Sevrez \& Bourdin, 2015). Starosta (2006) emphasized that the most important element which determined success in most sports was a complex of specific kinaesthetic sensations and co-ordination abilities, which form the so-called feelings, e.g. ball feeling, water feeling, partner feeling, opponent feeling. This feeling, or sense, represents a manifestation of proprioception, which can be connected with joint position sense, force sense, movement sense, and spatial orientation (Jerosch \& Prymka, 1996). The above-mentioned factors are critical in a number of table tennis game moves, such as the skill needed in feeling the rotation of a served ball, changing the direction of the ball during game play or modifying the speed at which the ball is hit (as well as adjusting to the movement rate and change in the direction of the flying ball—Hotz \& Muster, 1993). Additionally, the selection of gripping the racket at a specific angle (whether the racket is open or closed) is also probably a skill linked to proprioception.

One of the first definitions of proprioception says, that proprioception is "the perception of joint and body movement as well as position of the body, 
or body segments, in space, and the perceptions of the relative flexions and extensions of our limbs" (Sherington, 1906; Han, Waddington, Adams, Anson, \& Liu, 2016). Proprioception is currently defined as a complex entity encompassing several different components, such as the sense of: position, velocity, movement, and force. Proprioceptive sensation is derived peripherally from mechanoreceptors located in muscles, joint capsules, tendons, ligaments and skin, which are stimulated by mechanical deformation (McCloskey, 1978; Olson, et al., 2004). Saying shortly-proprioception can be defined as the ability of an individual to determine body segment positions and movements in space and is based on sensory signals provided to the brain from muscle, joint, and skin receptors (Goble, 2010).

In previous studies, the aptitudes connected with proprioception have been mostly determined in laboratory settings by means of goniometers, inclinometers, or dynamometers (Bańkosz, 2012, 2015; Dover \& Powers, 2003; Zatoń, Błacha, Jastrzębska, \& Słonina, 2009). To examine proprioceptive mechanisms, different techniques have been reported in literature. There are three main testing techniques for assessing proprioception: the threshold to detection of passive motion, joint position reproduction, also known as joint position matching (or sense), and active movement extent discrimination assessment (Han, et al., 2016). Joint position sense is one of the most commonly used measures of proprioception. Determining joint position sense involves measuring the accuracy of jointangle replication, which can be conducted actively or passively and in an open or closed chain environment. The sense of force, commonly evaluated using force reproduction, has also been used as a measure of proprioception (Proske \& Gandevia, 2012). Joint position sense and force reproduction were evaluated as a measure of proprioception in table tennis in previous research studies with variable and ambiguous results (Bańkosz, 2012, 2015). Several studies have presented views on the likelihood of correlation between the level of proprioception or ball sense and performance in table tennis (Bańkosz, 2015; Li, Lu, \& Wang, 2000). However, the complexity of the factors, which have impact on the development of the players, is substantial, while their mutual integration and manifestation during game playing may occur in very different arrangements (Kondric, et al., 2013). Therefore, the evaluation of these factors should take into consideration this integration, coexistence, and relationships between each other. Consequently, it is essential to evaluate the manifestations of abilities and skills used during game play. It would be interesting to measure proprioception in integration of the factors most commonly viewed as the most important motor ability in table tennis (as it was written above), i.e. speed, in particular with quick reaction.

To our best knowledge no studies have evaluated proprioception (viewed as an accurate movement based on proprioceptive sensibility) with the necessity to perform, i.e. react quickly that is under conditions observed in various sports, including table tennis.

The aim of this study was to evaluate replication accuracy of a specific range of motions (pronation and supination movements of the forearm at the elbow joint) and force of hand-pressing under conditions of limited time (starting the activity as fast as possible in response to a visual signal). Therefore, we evaluated such factors as the joint position sense and the pressure force reproduction sense as measures of proprioception under conditions of quick reaction. Necessity of quick reaction causes a specific situation that simulates natural conditions of table tennis game play, thus integrating proprioception with speed. The hypothesis was tested that both male and female table tennis players would obtain more accurate results than controls in tasks concerning the accuracy of movement replication. This would suggest the relationship between table tennis training and the level of proprioception. Confirmation of the hypothesis would point to the importance of the sense of movements replication under condition of quick reaction in table tennis and provide opportunities for using the evaluation of this sense in the recruitment of table tennis players and in monitoring their training progress.

\section{Methods}

\section{Participants}

The study evaluated 40 table tennis players who had participated in the Polish table tennis classification tournaments (high level junior players classified as 1 to 64 in the national ranking) and 30 control peers, students from the third class of junior high school who declared as non-athletes. Every participant declared and pointed out his or her

Table 1. Characteristics of the examined groups: age, body height and body mass

\begin{tabular}{lccc}
\hline Group & $\begin{array}{c}\text { Age } \\
M(S D) \\
(\text { year })\end{array}$ & $\begin{array}{c}\text { Body height } \\
M(S D) \\
(\mathrm{cm})\end{array}$ & $\begin{array}{c}\text { Body mass } \\
M(\mathrm{SD}) \\
(\mathrm{kg})\end{array}$ \\
\hline $\begin{array}{l}\text { Table tennis male } \\
\text { players ( } \mathrm{n}=20)\end{array}$ & $17.25(0.83)$ & $177.50(4.60)$ & $68.70(2.51)$ \\
$\begin{array}{l}\text { Table tennis } \\
\text { female players } \\
(\mathrm{n}=20)\end{array}$ & $16.58(0.99)$ & $163.52(5.73)$ & $59.51(3.23)$ \\
$\begin{array}{l}\text { Control group }- \\
\text { males (n=15) }\end{array}$ & $16.00(0.00)$ & $174.03(5.90)$ & $66.19(3.22)$ \\
$\begin{array}{l}\text { Control group - } \\
\text { females (n=15) }\end{array}$ & $16.00(0.00)$ & $164.12(4.61)$ & $54.17(2.51)$ \\
\hline
\end{tabular}




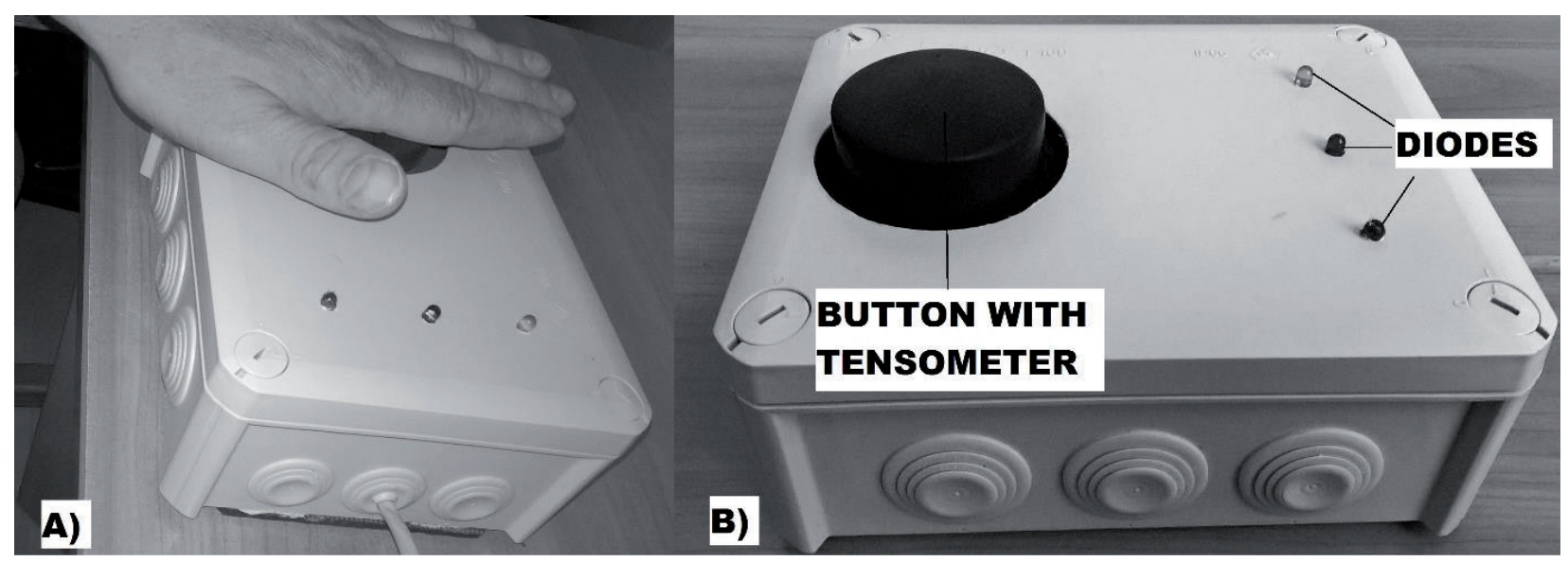

Figure 1. Hand positioning (A) and dynamometer (B)

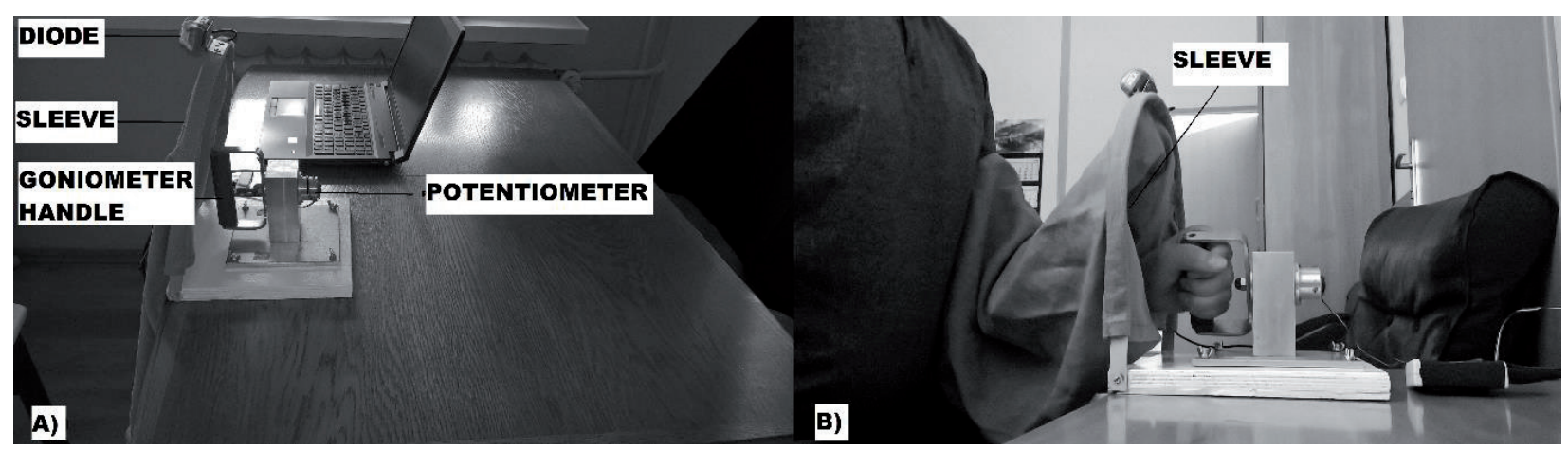

Figure 2. Goniometer (A) and position of participant (B)

dominant upper limb. The characterization of the groups is shown in Table 1. All the participants gave written consent for their participation in the examinations. The local ethics committee approved this study, and the institutional review board approved the research.

\section{Procedures and equipment}

The examinations were conducted in a separate room during morning hours. The research stand was composed of a goniometer and a dynamometer (see Figures 1 and 2).

The dynamometer (Fig. 1) consisted of a rigid box with an in-built button, with a strain gauge (KMM 20, made by Wobit, P.P.H. WObit E.K.J. Ober s.c., Poland) that recorded the pressure force. Next to the button were diodes which were switched on remotely from a computer by the test supervisor. The force values were recorded using Labview National Instruments version 2009 software with a NI USB 6009 analog-digital board (National Instruments, Austin, TX, USA). Sitting on a chair with adjustable height, the participant kept the hand on the button of the measuring device (with the elbow, flexed at right angle, near to the trunk) and, in pretrials, pressed it three times, using a target force of $20 \mathrm{~N}$. Upon reaching the force of $20 \mathrm{~N}$, a loud ring was sounded, and the participant was informed about the value of force he/she pressed. Next, in the proper test, the participant reproduced the pressure from the pre-trials from memory five times, being instructed to do this as fast as possible in response to a diode signal with no audio cue. The test was performed using both limbs with the same procedures. The maximal values of the pressure force (in newton) were considered as replicated values. Standard deviations of the replicated values were adopted as accuracy indices (expressed in newton), i.e. the indices of force sense, according to the following formula:

$$
s=\sqrt{\frac{1}{N-1} \sum_{i=1}^{N}\left(x_{i}-\bar{x}\right)^{2}}
$$

where $\mathrm{S}$ is the standard deviation, are the observed values of the sample items, $\bar{x}$ is the mean value of these observations, and $N$ is the number of observations in the sample. Therefore, it was adopted that a lower value of the index reflects a higher accuracy and, consequently, a higher level of force sense (as one of the components of proprioception integrated with quick reaction). The following two indices were recorded for further analysis:

F_R - accuracy of pressure force reproduction, the dominant limb

F_L - accuracy of pressure force reproduction, the non-dominant limb 
A goniometer (Fig. 2) is a device that allows a rotational movement using a handle held by the participant. The device was contained in an in-built potentiometer (rotary potentiometer with linear characteristics) that recorded changes in location of the handle. The diode in the device was switched on by the test supervisor remotely from a computer. Angular changes were monitored using Labview National Instruments version 2009 computer software, connected to the NI USB 6008 analogdigital board (National Instruments, Austin, TX, USA). Sitting on a chair with adjustable height, the participant held the handle so that a right-angle was formed between the upper arm and forearm and the elbow was near the participant's trunk (Fig. 2). The forearm axis coincided with the movement axis, while the third head of the metacarpal bone coincided with the rotation axis according to the requirements for the measurement of a range of motions. Before each series of test tasks, the initial position of the study participant was checked and corrected by the test supervisor. The participants were not familiarized with the equipment before the test. Firstly, they performed three pre-trials under visual control alternating pronation and supination movements of the forearm of the dominant arm (movement pattern), starting from the intermediate position (zero angle) to an angle of 45 degrees (to both sides - pronation and supination, in any direction first). Reaching the angle of 45 degrees (in both pronation and supination) was signalled by a loud bell which was switched on automatically. Next, in the proper test, the participant was asked to replicate the movement of the pre-trials (rotation of 45 degrees, separately, one by one: supination and pronation) five times in response to a diode signal (with no audio clue), attempting to start the movement as fast as possible. During these trials the participant was unable to see the forearm position as it was covered by a broad sleeve (Fig. 2). The next step involved examination of the non-dominant hand, with the same procedure. Computer software recorded the maximal range of motion in each direction as an angle replicated by the participant (in degrees). Joint position sense was determined in the tests by accuracy indices, which represented the standard deviation from the replicated angles, according to the following formula:

$$
s=\sqrt{\frac{1}{N-1} \sum_{i=1}^{N}\left(x_{i}-\bar{x}\right)^{2}}
$$

where $\mathrm{S}$ is standard deviation, are the observed values of the sample items, $\bar{x}$ is the mean value of these observations, and $N$ is the number of observations in the sample. Therefore, it was adopted that a lower value of the index (expressed in degrees) reflects higher accuracy and, consequently, a higher level of joint position sense (as a component of proprioception integrated with quick reaction). The following indices were taken for further analysis: S_R - index of supination accuracy, the dominant limb

S_L-index of supination accuracy, the non-dominant limb

P_R - index of pronation accuracy, the dominant limb

P_L - index of pronation accuracy, the non-dominant limb

\section{Statistics}

The indices obtained in the study were subjected to statistical analysis. Mean values, standard deviations, and coefficients of variation were computed. The distribution of variables was verified using the Shapiro-Wilk test. The results of this test demonstrated a multiple occurrence of non-normal distribution. Therefore, a group comparison was performed by means of the non-parametric MannWhitney's U test. The results obtained by the two study groups were compared for individual tests, with consideration for gender and the body side (the dominant and non-dominant limb). Accuracy of performance of individual tests was also compared between the dominant and non-dominant limbs for each group individually in male and female table tennis players and in the control group. The coefficient of variation was also evaluated for the results obtained by the groups in individual tests. The following interpretation of the coefficient was adopted: $\mathrm{V}<50 \%$ - low variation, $50 \%<\mathrm{V}<100 \%$ - moderate variation, $\mathrm{V}>100 \%$ - high variation.

\section{Results}

Mean values of the results obtained in each test were determined for each experimental group for the purpose of comparison. First, we compared the values of the indices of accuracy of pressure force reproduction and then the indices of accuracy of supination and pronation of the forearm.

In the group of women, significantly lower values of accuracy indices (indicative of a higher accuracy) in the tasks of force reproduction with the right and left limbs could be found more often in the athletes than in the controls (Table 2). For the right limb table tennis players were more accurate in the elbow joint position sense $(\mathrm{p}<.05)$. Substantial values (mostly over $50 \%$ ) can be observed for the coefficient of variation for accuracy indices.

In the force reproduction test, the results obtained by male athletes were not statistically significantly different from those in the control group (Table 3). Mean values of accuracy indices were, however, lower in table tennis players than in controls (Table 3). Similar to women, coefficients of variation for accuracy indices (F_L and F_R) were high. 
Table 2. Mean values of accuracy indices, standard deviations, and coefficients of variation for the control group and table tennis players in the test of force reproduction ( $N)$, $p$ values of the Mann-Whitney's $U$ test-females

\begin{tabular}{|c|c|c|c|c|c|}
\hline \multirow[b]{2}{*}{ Variable } & \multicolumn{2}{|c|}{ Control group $(n=15)$} & \multicolumn{2}{|c|}{ Table tennis players $(n=20)$} & \multirow{2}{*}{$\begin{array}{l}p \text { value (Mann- } \\
\text { Whitney's } U \text { test) }\end{array}$} \\
\hline & $M(S D)$ & $\begin{array}{l}\text { Coefficient of } \\
\text { Variation (\%) }\end{array}$ & $\mathrm{M}(\mathrm{SD})$ & $\begin{array}{l}\text { Coefficient of } \\
\text { variation (\%) }\end{array}$ & \\
\hline F_L & $.68(0.34)$ & 50.81 & $.49(0.31)$ & 63.75 & .11 \\
\hline F_R & $.60(0.36)$ & 60.06 & $.34(0.17)$ & 49.36 & $.02^{*}$ \\
\hline
\end{tabular}

Note. $F_{-} L$ - indices of accuracy of force reproduction, non-dominant limb; $F_{-} R$ - indices of accuracy of force reproduction, dominant limb.

Table 3. Mean values of accuracy indices, standard deviations, and coefficients of variation for the control group and table tennis players in the test of force reproduction ( $N)$, $p$ values of the Mann-Whitney's $U$ test-males

\begin{tabular}{|c|c|c|c|c|c|}
\hline \multirow{2}{*}{ Variable } & \multicolumn{2}{|c|}{ Control group $(n=15)$} & \multicolumn{2}{|c|}{ Table tennis players $(n=20)$} & \multirow{2}{*}{$\begin{array}{l}p \text { value (Mann- } \\
\text { Whitney's U test) }\end{array}$} \\
\hline & $\mathrm{M}(\mathrm{SD})$ & $\begin{array}{l}\text { Coefficient of } \\
\text { Variation (\%) }\end{array}$ & $M(S D)$ & $\begin{array}{l}\text { Coefficient of } \\
\text { variation (\%) }\end{array}$ & \\
\hline F_L & $.73(0.45)$ & 61.32 & $.53(0.33)$ & 62.92 & .12 \\
\hline$F_{-} R$ & $.70(0.55)$ & 78.79 & $.49(0.29)$ & 58.84 & .13 \\
\hline
\end{tabular}

Note. F_L - indices of accuracy of force reproduction, non-dominant limb; F_R - indices of accuracy of force reproduction, dominant limb.

Table 4. Mean values of accuracy indices, standard deviations, and coefficients of variation for the control group and table tennis players in the test of replication of forearm pronation and supination movements (degrees), $p$ values of the Mann-Whitney's $U$ test-females

\begin{tabular}{|c|c|c|c|c|c|}
\hline \multirow{2}{*}{ Variable } & \multicolumn{2}{|c|}{ Control group $(n=15)$} & \multicolumn{2}{|c|}{ Table tennis players $(n=20)$} & \multirow{2}{*}{$\begin{array}{c}p \text { value of U Mann- } \\
\text { Whitney test }\end{array}$} \\
\hline & $M(S D)$ & $\begin{array}{l}\text { Coefficient of } \\
\text { variation (\%) }\end{array}$ & $M(S D)$ & $\begin{array}{l}\text { Coefficient of } \\
\text { variation (\%) }\end{array}$ & \\
\hline S_L & $7.73(3.87)$ & 50.08 & $7.64(3.97)$ & 51.96 & .61 \\
\hline P_L & $13.96(8.02)$ & 57.48 & $7.85(4.72)$ & 60.15 & $.03^{*}$ \\
\hline S_R & $10.04(3.63)$ & 36.14 & $5.79(2.24)$ & 38.78 & $.00^{*}$ \\
\hline P_R & $12.98(10.08)$ & 77.68 & $8.00(4.38)$ & 54.82 & .08 \\
\hline
\end{tabular}

Note. S_L - accuracy indices, supination, non-dominant limb, P_L - accuracy indices, pronation, non-dominant limb, S_R - accuracy indices, supination, dominant limb, P_R - accuracy indices, pronation, dominant limb.

Table 5. Mean values of accuracy indices, standard deviations, and coefficients of variation for the control group and table tennis players in the test of replication of forearm pronation and supination movements (degrees), p values of U Mann-Whitney test-male

\begin{tabular}{|c|c|c|c|c|c|}
\hline \multirow[b]{2}{*}{ Variable } & \multicolumn{2}{|c|}{ Control group $(n=15)$} & \multicolumn{2}{|c|}{ TT players $(n=20)$} & \multirow{2}{*}{$\begin{array}{c}p \text { value of U Mann- } \\
\text { Whitney test }\end{array}$} \\
\hline & $\mathrm{M}(\mathrm{SD})$ & $\begin{array}{l}\text { Coefficient of } \\
\text { Variation (\%) }\end{array}$ & $M(S D)$ & $\begin{array}{l}\text { Coefficient of } \\
\text { Variation (\%) }\end{array}$ & \\
\hline S_L & $8.89(7.30)$ & 82.11 & $7.14(2.80)$ & 39.24 & .41 \\
\hline P_L & $7.71(3.32)$ & 43.03 & $7.77(3.74)$ & 48.17 & .97 \\
\hline S_R & $8.21(2.90)$ & 35.30 & $5.91(3.95)$ & 66.83 & $.03^{*}$ \\
\hline P_R & $10.38(3.51)$ & 33.86 & $6.90(3.41)$ & 49.47 & $.01^{*}$ \\
\hline
\end{tabular}

Note. S L - accuracy indices, supination, non-dominant limb, $P$ L - accuracy indices, pronation, non-dominant limb, S R - accuracy indices, supination, dominant limb, P_R - accuracy indices, pronation, dominant limb.

Table 6. The Mann-Whitney's U tests' $p$ values-a comparison of the results between the left and right limb in individual tests

\begin{tabular}{lccc}
\hline Variable & S_L \& S_R $_{1}$ & P_L \& P_R $_{-}$ & F_L \& F_R \\
\hline Control group $(n=30)$ & .09 & .15 & .42 \\
TT players $(n=40)$ & $.01^{*}$ & .39 & $.04^{*}$ \\
\hline
\end{tabular}

Note. S_L - accuracy indices, supination, non-dominant limb, $P_{-} L$ - accuracy indices, pronation, non-dominant limb, S_R - accuracy indices, supination, dominant limb, P_R - accuracy indices, pronation, dominant limb. 
In the test of replication of the range of motion, female tennis players were characterized by significantly lower values of accuracy indices in two cases ( $\mathrm{P} \_$and $\left.\mathrm{S} \_\mathrm{R}\right)$, although mean values were also lower in the other two cases (S_L and P_R) (Table 4). Similarly to the previous tasks, high values can be observed for the coefficients of variation for accuracy indices.

The accuracy indices of the replication of supination and pronation movements in the non-dominant limb were slightly lower in the group of table tennis male players than in the controls (Table 5). However, table tennis players performed supination and pronation movements with the dominant limb significantly more accurate than the non-athletes (Table 5). Similar to the previous tests, high values can be observed in the coefficients of variation for accuracy indices.

The Mann-Whitney's U-test performed for the dominant and non-dominant arms in individual groups and, therefore, evaluated lateral variation in terms of accuracy of the performed tasks, demonstrated that athletes were characterized by significant differences. Out of the three tasks, two (supination/pronation and pressure force) showed significant differences between the dominant and nondominant limbs in athletes (Table 6).

\section{Discussion and conclusions}

This study evaluated the accuracy of replication of the movement in the elbow joint (forearm supination and pronation) and hand pressure force under the conditions of quick reaction. Previous studies concerning proprioception have presented contradictory findings for the movement replication ability, defined as a joint position sense or force sense. Some studies have demonstrated that athletes are characterized by a better joint position sense compared to non-athletes. These studies have been based on soccer (Muaidi, Nicholson, \& Refshauge, 2009), basketball (Sevrez \& Bourdin, 2015), taekwondo (Fong, Tsang, \& Ng, 2013), rugby (Herrington, Horsley, \& Rolf, 2009), as well as handball (Panics, et al., 2008). Cho et al. (2017) pointed out that synchronized swimmers had fewer active joint repositioning errors in the shoulder, wrist, and ankle on land and in the hip and ankle underwater. Other studies, however, have emphasized that high-intensity training is likely to have a negative effect on the limb position sense (Barrack, Cook, \& Skinner, 1984; Dover, Kaminski, Meister, Powers, \& Horodyski, 2003) or that some types of sports (e.g. running) do not improve sense in the area of the joints that are involved $(\mathrm{Li}, \mathrm{Xu}, \&$ Hoshizaki, 2009). A few studies have explored proprioception in table tennis players, although the results have been relatively equivocal (Bańkosz, 2012, 2015; Jerosch, Thorwesten, \& Reuter, 1997; Li \& Pan, 2010).
The investigations performed in our study concerned joint position sense and force sense under the conditions of quick reaction. The study involved upper limbs, whose accuracy and speed seem to be critical to playing table tennis. Most of the movement replication tests using the dominant limb in the female group (two in three cases) revealed that the athletes performed the task significantly better than the non-athletes in the pressure test and the supination test. In the case of the nondominant limb, female athletes performed significantly better in one out of the three tests (pronation test). However, mean accuracy indices for female athletes were lower in all the tests (the lower the index, the better the task performance) compared to the control group. Male table tennis players performed more accurate than the controls in tests of movement replication for the dominant forearm (pronation and supination).

Undoubtedly, the evaluation of force sense and joint position sense under the condition of quick reaction points to the differences between the table tennis players and the control group - table tennis players manifested a higher level of accuracy based on proprioception than the control group. This may result from the specific sport activity, in which the proprioception-based movement differentiation integrated with quick reaction is critical. Differences between the groups of athletes and nonathletes were more pronounced that in previous studies (Bańkosz, 2012, 2015). This is undoubtedly linked to the conditions of reaction to a signal used in the present study and, therefore, to the necessity of a quick replication of the forearm position and pressure force (the fastest reaction possible). Han, Anson, Waddington, \& Adams (2014, 2015a) and Han, Anson, Waddington, Adams, \& and Liu (2015b) highlighted the importance of ankle proprioception in sporting success. They measured ankle proprioception of elite athletes and found that the ankle proprioception scores were significantly predictive of sport performance level in aerobic gymnastics, soccer, swimming, badminton, and sports dancing. The authors also found that proprioception at the shoulder and spine were significantly associated with competitive level in these sports. The ankle proprioception was also correlated most strongly with sport competition level and was the most significant factor of sports performance (Han, et al., 2015b). Similarly, regarding the results of our study it can be presumed that the tools and methodology used in the study enable the evaluation of important elements which may be critical to the level of achievement in table tennis. It can be also concluded that the method might be useful for monitoring training progress and even in recruitment of athletes for the sport, but more research is needed. 
It should also be emphasized that mean accuracy indices for replication in each task were lower in athletes compared to the control group. It was adopted that lower indices indicated better results. However, significant differences between the two groups in replication of pronation and supination movements and force reproduction were found mainly for the dominant limb. This most likely resulted from the level of sense on the dominant side, which, due to the sport specificity, is higher in both male and female players compared to the control group. This is consistent with the observations presented in previous studies (Bańkosz, 2015). This observation was also supported by the results of comparison of dominant and non-dominant sides in both groups. In athletes (both women and men), substantial differences were found between the limbs twice (supination and force reproduction). This is probably connected with practising of table tennis. Lateral differentiation in proprioception of the upper limbs is most likely due to the use of the dominant limb during playing, which, as stated before, is related to the necessity of differentiation of the position of the hand, forearm, arm and muscular tension in their area. A substantial differentiation, as a result of practising of a specific sport, has been confirmed by some authors. Starosta (2001) found that the specificity of a given sport, expressed by the dominance of either symmetric or asymmetric movements, was responsible for the laterality regarding the precision of kinaesthetic perceptions. Physical loads induced differences in the movement precision of the left and right upper limbs in wrestlers, sailors, and windsurfers.

Some authors argue, however, that differences in the sense of position of the joint are not observed in study participants. King, Harding, and Karduna (2016) compared the accuracy of replication of angles in the elbow and shoulder joints in both limbs and found that there were no significant differences in angular joint position sense errors between the joints. Cug, Wikstrom, Golshaei, and Kirazci (2016) found that limb dominance did not influence knee-joint proprioception when tested in an open kinetic chain using passive repositioning in football players group. Undoubtedly, the problems of laterality, especially lateral differentiation of proprioception, are yet to be explored.

It is also noticeable that distribution of the results varied depending on the type of test. For example, no significant differences were found between the groups in force reproduction tests in men. These differences were found, however, in certain tests of the forearm supination and pronation replication. A similar pattern was observed in women, although, as emphasized above, more statistically significant differences were found between the groups. This different distribution of the results in the groups is likely to have been caused by the independence and non-homogeneity of the two types of sense (either joint position sense or force sense). This observation is consistent with previous findings (Bańkosz, 2015; Juras, Waśkiewicz, \& Mynarski, 1993).

Analysis of the coefficients of variation reveals that the tests of angle replication and force reproduction are characterized by a substantial spread of results in both groups. In most cases, the values were close to or higher than $50 \%$. This suggests a substantial differentiation between the groups in terms of reproducibility of results. Perhaps this is typical of the examinations of joint position sense or force sense, which are the components of proprioception characterized by substantial variation and dependent on many factors (e.g. focus of attention, mood and time of day), which has been emphasized in other studies (Bańkosz, 2015; Kollarovits $\&$ Teplicka, 1999). This can be regarded as a limitation of the study. The next limitation of our study is the analysis of the values of reproduced force and range of movement. In this study we assessed the reproduction of absolute value of force - it was estimated at $20 \mathrm{~N}$ for every participant, as well as the range of movement of 45 degrees of supination and pronation. Future studies should take into account the assessment of relative values (e.g. 50\% of maximum pressure force of each participant), which can give different results and conclusions than those presented in this work.

The tests performed in the study revealed that both female and male table tennis players were characterized by a higher level of forearm position sense during performing the fastest possible pronation and supination movements in most of the tasks. Therefore, it can be presumed that joint position sense is an important factor in table tennis. The results of the tests concerning hand force sense performed by female athletes were better compared to the control group. This suggests the importance of this factor in table tennis and opportunities for using the methodology used here to monitor training. In the male group, despite the mean values being lower than in the control group in each test (lower means reflected better results), the differences were not statistically significant. Greater differences between the groups in all the tasks concerned the dominant limb, which can be linked to the sport specificity, where accuracy of the playing limb is critical. The above observations are also confirmed by the differences between the dominant and non-dominant limb during performance of the tasks by athletes who were better than controls at performing the task using the playing hand. 


\section{References}

Ak, E., \& Kocak, S. (2010). Coincidence-anticipation timing and reaction time in youth tennis and table tennis players. Perceptual and Motor Skills, 110, 879-887. doi: 10.2466/PMS.110.3.879-887

Akpinar, S., Devrilmez, E., \& Kirazci, S. (2012). Coincidence-anticipation timing requirements are different in racket sports Perceptual and Motor Skills: Exercise and Sport, 115, 1-13. doi: 10.2466/30.25.27.PMS.115.5.

Bańkosz, Z. (2012). The kinesthetic differentiation ability of table tennis players. Human Movement, 13, 16-21. doi: 10.2478/V10038-011-0049-Z

Bańkosz, Z. (2015). Reproduction of movement range and pressure force of the upper limbs in table tennis players. Trends in Sport Sciences, 1, 26-37.

Barrack, R.L., Cook, S.D., \& Skinner, H.B. (1984). Proprioception of the knee joint. Paradoxical effect of training. American Journal of Physical Medicine and Rehabilitation, 63, 175-181.

Bhabhor, M.K., Vidja, K., Bhanderi, P., Dodhia, S., Kathrotia, R., \& Joshi, V. (2013). A comparative study of visual reaction time in table tennis players and healthy controls. Indian Journal of Physiology and Pharmacology, 57, 439-442.

Can, S., Kilit, B., Arslan, E., \& Suveren, S. (2014). The comparison of reaction time of male tennis players, table tennis players and the ones who don't exercise at all in 10 to 12 age groups. Nigde University Journal of Physical Education and Sport Sciences, 8, 195-201.

Cho, N.M.Y., Giorgi H.P., Liu K.P.Y., Bae Y.H., Chung L.M.Y., Kaewkaen K., \& Fong, S.S.M. (2017). Proprioception and flexibility profiles of elite synchronized swimmers. Perceptual and Motor Skills, 124, 1151-1163. doi: $10.1177 / 0031512517724965$

Cug, M., Wikstrom, E.A., Golshaei, B., \& Sadettin Kirazci, S. (2016). The effects of sex, limb dominance, and soccer participation on knee proprioception and dynamic postural control. Journal of Sport Rehabilitation, 25, 31-39. doi: $10-1123 /$ jsr.2014-0250

Dover, G., \& Powers, M.E. (2003). Reliability of joint position sense and force-reproduction measures during internal and external rotation of the shoulder. Journal of Athletic Training; 38, 304-310.

Dover, G.C., Kaminski, T.W., Meister, K., Powers, M.E., \& Horodyski, M. (2003). Assessment of shoulder proprioception in the female softball athlete. American Journal of Sports Medicine, 31, 431-437. doi: 10.1177/03635465030310031801

Erdil, G., Durusoy, F., \& Acar, M. (1991). The optical and acoustic reaction time values compartment between the elite table tennis players who exercise regularly and non-exercising people. Turkish Journal of Sports Medicine, $26,11-17$

Faber, I.R., Nijhuis-Van Der Sanden, M.W., Elferink-Gemser, M.T., Oosterveld, F.G. (2015). The Dutch motor skills assessment as tool for talent development in table tennis: a reproducibility and validity study. Journal of Sports Sciences, 33, 1149-1158. doi: 10.1080/02640414.2014.986503

Fong, S.S.M., Tsang, W.W.N., \& Ng, G.Y.F. (2013). Lower limb joint sense, muscle strength and postural stability in adolescent taekwondo practitioners. International SportMed Journal, 14, 44-52.

Goble, D.J. (2010). Proprioceptive acuity assessment via joint position matching: From basic science to general practice. Physical Therapy, 90, 1176-1184. doi: 10.2522/ptj.20090399

Han, J., Anson, J., Waddington, G., \& Adams, R. (2014). Sport attainment and proprioception. International Journal of Sports Science and Coaching, 9, 159-170. doi: 10.1260\%2F1747-9541.9.1.159

Han, J., Anson, J., Waddington, G., \& Adams, R. (2015a). Level of competitive success achieved by elite athletes and multi-joint proprioceptive ability. Journal of Science and Medicine in Sport, 18, 77-81. doi: 10.1016/j. jsams.2013.11.013

Han, J., Anson, J., Waddington, G., Adams, R., \& Liu, Y. (2015b). The role of ankle proprioception for balance control in relation to sports performance and injury. BioMed Research International, Vol. 2015, Article ID 842804. doi: $10.1155 / 2015 / 842804$

Han, A., Waddington, G., Adams, R., Anson, J., \& Liu, Y. (2016). Assessing proprioception: A critical review of methods. Journal of Sport and Health Science, 5, 80-90. doi: 10.1016/j.jshs.2014.10.004

Herrington, L., Horsley, I., \& Rolf, C. (2009). Evaluation of shoulder joint position sense in both asymptomatic and rehabilitated professional rugby players and matched controls. Physical Therapy in Sport, 11, 18-22. doi: 10.1016/j.ptsp.2009.10.001

Hotz, A., \& Muster, M. (1993). Tischtennis - lehren und lernen: individuelles lernen durch differenziertes lehren (pp. 14-23). [Table tennis: teaching and learning: Individual learning through differentiated teaching. In German.] Aachen, Germany: Meyer \& Meyer.

Hudetz, R. (2005). Tenis stołowy 2000 [Table tennis 2000. In Polish.]. Łódź, Poland: Wydawnictwo PPHU Modest.

Jerosch, J., \& Prymka, M. (1996). Proprioception and joint stability. Knee Surgery, Sports Traumatology, Arthroscopy, $4,171-179$.

Jerosch, J., Thorwesten, L., \& Reuter, M. (1997). Proprioceptive capabilities of the elbow joint in elite female table tennis, players. Deutsche Zeitschrift für Sportmedizin, 48, 43-48. 
Juras, G., Waśkiewicz, Z., \& Mynarski, W. (1993). Zdolność różnicowania kinestetycznego w świetle analizy czynnikowej. [Kinesthetic differentiation ability in factor analysis. In Polish.]. Zeszyty Metodyczno-Naukowe AWF Katowice, 4, 55-67.

King, J., Harding, E., \& Karduna, A. (2013). The shoulder and elbow joints and right and left sides demonstrate similar joint position sense. Journal of Motor Behaviour, 45, 479-486. doi: 10.1080/00222895.2013.832136

Kollarovits, Z., \& Teplicka, S. (1999). Stability of kinesthetic differentiation abilities in the period of several months. Telesna Vychova \& Sport, 9, 45-48.

Kondric, M., Zagatto, A.M., \& Sekulić, D. (2013). The physiological demands of table tennis: A review. Journal of Sports Science and Medicine, 12, 362-370.

Łapszo, J. (2002). The speed of sequential movements in table tennis studied under simulated conditions with respect to range, body involvement and direction. International Journal of Table Tennis Sciences, 4/5, 19-28.

Li, J., \& Pan, H. (2010). Proprioception of foot and ankle complex in young regular practitioners of wu-shu, table tennis and running. In R. Jensen, W. Ebben, E. Petushek, C. Richter \& K. Roemer (Eds.), Proceedings of the 28th International Conference on Biomechanics in Sports, Marquette, Michigan, July 19-23, 2010. Retrieved from: https://ojs.ub.uni-konstanz.de/cpa/article/view/4540

Li, H.S., Lu, T.Y., \& Wang, P.Y. (2000). Testing and evaluation model of children's ball sense in table tennis. Journal of Tianjin Institute of Sport, 15, 72-74.

Li, J.-X., Xu, D.-Q., \& Hoshizaki, B. (2009). Proprioception of foot and ankle complex in young regular practitioners of ice hockey, ballet dancing and running. Research in Sports Medicine, 17, 205-216. doi: 10.1080/15438620903324353

McCloskey, D.I. (1978). Kinesthetic sensibility. Physiological Reviews, 58, 763-820.

Muaidi, Q.I., Nicholson, L.L., \& Refshauge, K.M. (2009). Do elite athletes exhibit enhanced proprioceptive acuity, range and strength of knee rotation compared with non-athletes? Scandinavian Journal of Medicine and Science in Sports, 19, 103-112. doi: 10.1111/j.1600-0838.2008.00783.x

Olsson, I., Lund, H., Henriksen, M., Rogind, H., Bliddal, H., \& Danneskiold-Samsøe, B. (2004). Test-retest reliability of a knee joint position sense measurement method in sitting and prone position. Advances in Physiotherapy, 6, 37-47. doi: 10.1080/14038190310009894

Panics, G., Tallay, A., Pavlik, A., \& Berkes, I. (2008). Effect of proprioception training on knee joint position sense in female team handball players. British Journal of Sports Medicine, 42, 472-476. doi:10.1136/bjsm.2008.046516

Proske, U., \& Gandevia, S.C. (2012). The proprioceptive senses: Their roles in signalling body shape, body position and movement, and muscle force. Physiological Reviews, 92, 1651-1697. doi: 10.1152/physrev.00048.2011

Sevrez, V., \& Bourdin, C. (2015). On the role of proprioception in making free throws in basketball. Research Quarterly for Exercise and Sport, 86, 274-280. doi:10.1080/02701367.2015.1012578

Sherrington, C.S. (1906). The integrative action of the nervous system. Cambridge: Cambridge University Press.

Starosta, W. (2006). The concept of modern training in sport. Studies in Physical Culture and Tourism, 13, 9-23.

Starosta, W. (2001). Uwarunkowania stronnego zróżnicowania dokładności ruchów u wysoko zaawansowanych zawodników uprawiających rozmaite dyscypliny sportowe. [Factors affecting lateral differentiation of movements in elite athletes of various sports. In Polish] Medycyna Sportowa, 17, 152-160.

Zatoń, M., Błacha, R., Jastrzębska, A., \& Słonina, K. (2009). Repeatability of pressure force during elbow flexion and extension before and after exercise. Human Movement, 10, 137-143.

Submitted: November 14, 2018

Accepted: January 13, 2021

Published Online First: May 13, 2021

Correspondence to:

Ziemowit Bańkosz

Department of Physical Education and Sports,

University School of Physical Education in Wrocław,

Poland

Al. Paderewskiego 35

51-612 Wrocław, Poland.

Email: ziemowit.bankosz@awf.wroc.pl 